\title{
Journal of Pharmaceutical Regulatory Affairs: Filling the Gap between Science and Usability
}

\section{Helmut Niederhofer*}

Department of child Psychiatry, Rodewisch Psychiatric Hospital, Germany

I welcome the establishment of the Journal of Pharmaceutical Regulatory affairs, because there is a need to optimize understandable information of patients about e.g. economic aspects of various therapeutic options. Several recent developments underline the need of such a journal:

Firstly, in the last few years the number of scientific medical journals has been extremely increased. Actually there are one or more specific journals for every field in medical research. The articles of those journals focus mainly on medical aspects. Only some psychological or psychiatric journals focus on items like life quality, economics - but the usability of therapeutic options is nearly never described.

Secondly, the number of therapeutic options has significantly increased. Additionally patients have to be informed extensively about effects and adverse side effects of those options. Again, there are almost no studies about the usability of information about those options.

Last but not least, there are many efforts to give names to new medications. Associations with a variety of terms as well as with similar names of other medications are investigated. There are specific surveys, to be completed only by physicians, but never by patients.

Altogether, I would wish this journal to focus on understandable information for patients and to develop new ideas to optimize this information. Finally, the WHO requests complete information for our patients - every effort should be done not only to respect this recommendation, but also to present this information in an understandable manner for our patients.
*Corresponding author: Helmut Niederhofer, PhD, Director, Department of child Psychiatry, Rodewisch Psychiatric Hospital, Germany, Email: Helmut.Niederhofer@skhro.sms.sachsen.de

Received May 29, 2012; Accepted May 30, 2012; Published June 01, 2012

Citation: Niederhofer H (2012) Journal of Pharmaceutical Regulatory Affairs: Filling the Gap between Science and Usability. Pharmaceut Reg Affairs 1:e109. doi:10.4172/2167-7689.1000e109

Copyright: (C) 2012 Niederhofer H . This is an open-access article distributed under the terms of the Creative Commons Attribution License, which permits unrestricted use, distribution, and reproduction in any medium, provided the original author and source are credited. 